\title{
Self-Esteem and the Quality of Romantic Relationships
}

\section{Ruth Yasemin Erol and Ulrich Orth}

\author{
University of Bern
}

\begin{abstract}
This article has been accepted for publication but has not been through the copyediting, typesetting, pagination, and proofreading process. This article may not exactly replicate the final, authoritative version published in the journal. It is not the copy of record. Please cite this article as follows:
\end{abstract}

Erol, R. Y., \& Orth, U. (2016). Self-esteem and the quality of romantic relationships. European Psychologist, 21, 274-283.

http://dx.doi.org/10.1027/1016-9040/a000259

\section{Author Note}

Ruth Yasemin Erol and Ulrich Orth, Department of Psychology, University of Bern, Bern, Switzerland.

Correspondence concerning this article should be addressed to Ruth Yasemin Erol, Department of Psychology, University of Bern, Fabrikstrasse 8, 3012 Bern, Switzerland. E-mail: ruthyasemin.erol@psy.unibe.ch. 


\begin{abstract}
The relation between self-esteem and romantic relationships has been the focus of many research studies. In this article, we review theoretical perspectives and available evidence on (a) the effect of people's self-esteem on the quality of their romantic relationships, (b) the effect of self-esteem similarity between partners on relationship quality, and (c) the psychological mechanisms that might account for the link between self-esteem and relationship quality. Overall, the evidence suggests that high self-esteem is beneficial in romantic relationships. Furthermore, research using data from both partners of couples suggests that high self-esteem has a positive effect also on the partner's happiness with the relationship. However, research indicates that the degree of selfesteem similarity between partners does not influence the couple's relationship satisfaction. Although evidence suggests that perceived regard and secure attachment between the partners explains why self-esteem is beneficial in romantic relationships, future research is needed to examine in more detail the mechanisms through which self-esteem contributes to a happy relationship.
\end{abstract}

Keywords: self-esteem, romantic relationships, relationship satisfaction, similarity, dyadic effects 
Self-Esteem and the Quality of Romantic Relationships

Many researchers, practitioners, and laypeople alike believe that self-esteem influences whether individuals lead a satisfying life. A growing body of research suggests that the individual's level of self-esteem has consequences for the well-being and success in important life domains (for a review, see Orth \& Robins, 2014). For example, self-esteem predicts a more satisfying work life (Kuster, Orth, \& Meier, 2013; Orth, Robins, \& Widaman, 2012) and better physical and mental health (Sowislo \& Orth, 2013; Trzesniewski et al., 2006). Clearly, crosssectional research shows that self-esteem is positively correlated with relationship satisfaction (Barnett \& Nietzel, 1979; Fincham \& Bradbury, 1993; Murray, Holmes, \& Griffin, 1996a, 1996b; Sciangula \& Morry, 2009; Shackelford, 2001; Tackett, Nelson, \& Busby, 2013; Voss, Markiewicz, \& Doyle, 1999; Whisman, Uebelacker, Tolejko, Chatav, \& McKelvie, 2006; but see Cramer, 2003). However, does self-esteem influence whether individuals have satisfying romantic relationships?

In this paper, we review theoretical perspectives and available evidence on (a) the effect of people's self-esteem on the quality of their romantic relationships, (b) the effect of self-esteem similarity between partners on relationship quality, and (c) the psychological mechanisms that might account for the link between self-esteem and relationship quality. However, before turning to these issues, we first provide definitions of self-esteem and relationship quality and briefly describe how self-esteem and relationship quality develop during adulthood.

Self-esteem is defined as an individual's subjective evaluation of his or her worth as a person (Leary \& Baumeister, 2000). A person with high self-esteem "considers himself [or herself] worthy; he [or she] does not necessarily consider himself [or herself] better than others" (Rosenberg, 1965, p. 31); thus, self-esteem involves the feelings of self-respect and self- 
acceptance but not the feelings of superiority and entitlement that are typical for narcissistic selfviews (Ackerman et al., 2011). Research suggests that self-esteem increases during adolescence and young adulthood, continues to increase during middle adulthood, peaks at about age 50 to 60 years, and then gradually decreases into old age (for reviews, see Orth \& Robins, 2014; Trzesniewski, Donnellan, \& Robins, 2013).

Relationship quality comprises "a number of dimensions and evaluations" (Spanier \& Lewis, 1980), including relationship adjustment and relationship satisfaction (Glenn, 2003). Research generally suggests that measures of relationship adjustment and relationship satisfaction show high convergent validity (Heyman, Sayers, \& Bellack, 1994). According to Bradbury, Fincham, \& Beach (2000), one reason for the strong scientific interest in relationship satisfaction is its significance for personal and family well-being. The development of relationship satisfaction has been examined in a number of studies. Whereas some studies found a U-shaped curve with a decrease during the first years of the relationship and an increase in subsequent years (e.g., Orbuch, House, Mero, \& Webster, 1996), others reported a continuous decrease over time (e.g., Karney \& Bradbury, 1997; VanLaningham, Johnson, \& Amato, 2001). Importantly, Lavner, Bradbury, and Karney (2012) found three distinct trajectories for relationship partners: the first trajectory began high and remained high, the second began at an intermediate level and showed a small decrease, and the third began low and showed a substantial decrease. Because couples who experience decreasing relationship satisfaction are more likely to break up in the future (Karney \& Bradbury, 1997), it is important to identify the factors that account for change in relationship satisfaction.

\section{Effects of People's Self-Esteem on the Quality of Romantic Relationships}


Although in this review we focus on effects of self-esteem on romantic relationships, it is important to address also the possibility that the causal direction might be reverse-i.e., effects of romantic relationships on self-esteem. In fact, the hypothesis that relationship satisfaction influences self-esteem has intuitive appeal, as close relationships are assumed to be an important source of self-esteem (Harter, 2006; Swann \& Bosson, 2010). Moreover, sociometer theory-a prominent theory on self-esteem—suggests that self-esteem reflects the subjectively perceived own relational value (Leary, 2012; Leary \& Baumeister, 2000). Sociometer theory is based on the notion that humans have an inherent desire for interpersonal relationships because of their need for belongingness and acceptance (Baumeister \& Leary, 1995; Leary, 2004). In this theory, selfesteem is conceptualized as a gauge that monitors the individual's interactions with other people and provides feedback to the individual about the degree to which his or her behavior is socially acceptable. Thus, sociometer theory assumes that self-esteem is influenced by the individual's perception and interpretation of others' reactions toward the self (Leary \& Baumeister, 2000). Consequently, this perspective suggests that a person's self-esteem suffers if the person realizes that his or her relationship partner is dissatisfied with the relationship and that the person's selfesteem increases if the person perceives that his or her partner is happy with the relationship.

However, the available longitudinal evidence supports the conclusion that self-esteem influences relationship satisfaction rather than that relationship satisfaction influences selfesteem. Using longitudinal data across 12 months, Fincham and Bradbury (1993) found that selfesteem at Time 1 was correlated with relationship satisfaction at Time 2 in both men and women, whereas relationship satisfaction at Time 1 was correlated with self-esteem at Time 2 in men only. In a study by Neyer and Asendorpf (2001), self-esteem predicted relationship quality four years later, whereas relationship characteristics did not predict change in self-esteem. In a longitudinal study with five waves of data, self-esteem consistently predicted relationship 
satisfaction at later waves, controlling for previous levels of relationship satisfaction; however, relationship satisfaction did not predict change in self-esteem (Orth et al., 2012). Also, in a longitudinal study with a large sample of young adults, self-esteem prospectively predicted the quality of their romantic relationship (Johnson \& Galambos, 2014). Moreover, longitudinal research suggests that self-esteem prospectively predicts other outcomes in the relationship domain such as social support and social network size whereas social support and social network size did not predict change in self-esteem (Marshall, Parker, Ciarrochi, \& Heaven, 2014). It should be noted that a recent longitudinal study did not find evidence for prospective effects between a person's self-esteem and his or her relationship satisfaction (Schaffhuser, Wagner, Lüdtke, \& Allemand, 2014). In contrast, Mund, Finn, Hagemeyer, Zimmermann, and Neyer (2015) found evidence for reciprocal prospective effects between self-esteem and relationship quality. Nevertheless, the available evidence provides stronger support for the hypothesis that self-esteem influences relationship satisfaction rather than, vice versa, that relationship satisfaction influences self-esteem.

A possible reason for this pattern of results is that self-esteem is a relatively stable characteristic of individuals throughout the adult life span, comparable to broad personality traits such as the Big Five personality factors (Donnellan, Kenny, Trzesniewski, Lucas, \& Conger, 2012; Kuster \& Orth, 2013; Trzesniewski, Donnellan, \& Robins, 2003). Moreover, the pattern of results is consistent with research suggesting that self-esteem prospectively predicts satisfaction and success in other important life domains (besides relationships) such as work and health (Judge \& Hurst, 2008; Kuster et al., 2013; Orth et al., 2012; Salmela-Aro \& Nurmi, 2007; Stinson et al., 2008; Trzesniewski et al., 2006).

Importantly, a person's self-esteem can not only have an effect on his or her own relationship satisfaction (i.e., an effect which is called an actor effect), but also on his or her 
partner's satisfaction (i.e., an effect which is called a partner effect). One model that can be used to estimate actor and partner effects is the actor-partner interdependence model (APIM; Kenny \& Cook, 1999; Kenny, Kashy, \& Cook, 2006), which allows testing the dyadic nature of the relationship. An important statistical advantage of the APIM is that it accounts for the nonindependence of responses of the two partners involved in a couple (Kenny \& Ledermann, 2010). An example of the APIM is presented in Figure 1. The actor effect $a$ represents the effect of each partner's self-esteem on his or her own relationship satisfaction. The partner effect $p$ represents the effect of each person's self-esteem on his or her partner's relationship satisfaction. Finally, the model controls for the correlation between the partners' self-esteem (denoted as $r$ ) to account for systematic covariation of the predictor variables, and the model also controls for the correlation between the partners' relationship satisfaction to account for systematic covariation of the outcome variables that is unexplained by the model.

A growing body of research has used the APIM to test whether self-esteem has partner effects on the quality of romantic relationships. Some studies found supporting evidence for partner effects. Murray, Holmes, and Griffin (2000) examined dating and married couples, reporting a small but significant partner effect. Robinson and Cameron (2012) surveyed a sample of dating couples and found significant partner effects of self-esteem on relationship satisfaction and relationship commitment. In a recent study, we used data from five independent studies (Erol \& Orth, 2013). In all five studies, the results suggested that there is a partner effect of self-esteem on relationship satisfaction. However, other studies reported only partial evidence, or no evidence at all, for partner effects. Using a sample of dating couples, Jones and Cunningham (1996) did not find a partner effect. Murray, Holmes, and Griffin (1996b) examined a sample of young adults and found that women's self-esteem but not men's self-esteem had a partner effect. Similarly, in a study by Tackett, Nelson, and Busby (2013) with a large sample of dating and married couples, 
self-esteem did not have a partner effect. And finally, in a longitudinal study by Schaffhuser et al. (2014), no partner effect of self-esteem on relationship satisfaction emerged.

To provide further information on the relative size of actor and partner effects of selfesteem on relationship satisfaction, for this review we meta-analytically aggregated the findings across the five studies included in our research (Erol \& Orth, 2013). It should be noted that the five samples included different types of couples (i.e., dating, cohabiting, and married), couples with differing duration of relationship (i.e., several weeks to several decades), and participants from different developmental periods (i.e., late adolescence to old age). Thus, the samples covered a broad range of participants, which increases the generalizability of the findings. For the meta-analytic computations, we used the SPSS macros written by Daniel B. Wilson (Lipsey \& Wilson, 2001, Appendix D). All computations with effect sizes were made using Fisher's $Z_{\mathrm{r}}$ transformations. For computing the weighted mean effect sizes, we used random-effects models and study weights with $w=n-3$ (Raudenbush, 2009). The results are presented in Table 1 . The weighted mean actor effect of self-esteem was .26 ( $p<.05)$, corresponding to a medium-sized effect according to Cohen (1988). The weighted mean partner effect was .15 $(p<.05)$, corresponding to a small to medium-sized effect. Although these actor and partner effects are not large, we believe that they are important: given that relationship satisfaction is a construct influenced by multiple factors, the predictive power of each single factor is necessarily limited (Bradbury et al., 2000). Moreover, the effects of self-esteem tended to be larger than the corresponding actor and partner effects of the Big Five personality traits on relationship satisfaction (Dyrenforth, Kashy, Donnellan, \& Lucas, 2010). Finally, we examined the correlation between the partners' self-esteem, which indicates the average degree of similarity between partners - an issue to which we return in the next section. The weighted mean self-esteem similarity between partners was $.15(p<.05)$, corresponding to a small to medium-sized effect. 
In addition, for this review we meta-analytically aggregated findings from two longitudinal studies reported in Erol and Orth (2014), using the same procedures as described above. In this research, we used dyadic data to test the effects of self-esteem development among the partners of a couple on the development of relationship satisfaction. Relationship satisfaction was modeled as a couple-level process (i.e., as a latent variable that captured the degree of relationship satisfaction shared by the partners involved in the couple). The results are reported in Table 2. Across studies, a high initial level of self-esteem of each partner predicted a high initial level of the partners' common relationship satisfaction with .29 $(p<.05)$. More importantly, positive change in self-esteem of each partner predicted positive change in the partners' common relationship satisfaction with $.24(p<.05)$. It should be noted that - given that the models simultaneously examined the effects of both partners' self-esteem - the cumulative effects of the partners' self-esteem are twice as large as the individual effects. Thus, there is evidence that the development of self-esteem of relationship partners contributes significantly to the development of the quality of the partners' relationship.

\section{Effects of Self-Esteem Similarity Among Partners on the Quality of Romantic Relationships}

Another possible influence of self-esteem on romantic relationships might be related to the degree of similarity between the members of a couple. Overall, theory suggests that similarity rather than complementarity contributes to relationship quality, because similarity improves relationship functioning and because similar partners share similar emotional responses in daily life (Dyrenforth et al., 2010). Therefore, similarity in self-esteem might facilitate empathy among partners and increase the likelihood of positive social interaction. However, other theoretical perspectives suggest that self-esteem similarity might be maladaptive, given the relation between self-esteem and dominance (Zeigler-Hill, 2010). Research suggests that dominant people are more satisfied when interacting with submissive people, and that submissive people are more 
satisfied when interacting with dominant people (Dryer \& Horowitz, 1997). In sum, theory does not provide for clear-cut hypotheses with regard to the question of whether self-esteem similarity is beneficial or detrimental for the quality of relationships.

Research indicates that there is a small to medium-sized correlation between the selfesteem levels of relationship partners (e.g., Elfhag, Tynelius, \& Rasmussen, 2010; Murray et al., 2000; Whisman et al., 2006). Correspondingly, our own research with five heterogeneous samples of couples (Erol \& Orth, 2013) suggested that partners tend to have similar levels of selfesteem, as illustrated by the small to medium effect size shown in Table 1. Furthermore, individuals with high self-esteem describe their ideal partner as also having high self-esteem (Brown \& Brown, 2015). However, does similarity in self-esteem contribute to a satisfying relationship? As yet, research has neglected testing whether self-esteem similarity is beneficial for the partners' relationship. In a recent study, we addressed this question using longitudinal data from two large samples (Erol \& Orth, 2014). The results suggested that the degree of self-esteem similarity among partners did not predict either level or slope of the couple's relationship satisfaction. Moreover, we tested whether the pattern of findings differed between couples who participated at all waves (and, consequently, stayed together across the full study periods) and couples who had missing data at some waves (e.g., because the partners divorced or separated during the study periods); however, the results suggested that the null finding of self-esteem similarity held for both subsamples. These results are in line with findings on the effects of similarity in other personality characteristics of relationship partners such as the Big Five personality traits (Donnellan, Trzesniewski, Conger, \& Conger, 2007; Dyrenforth et al., 2010; Gattis, Berns, Simpson, \& Christensen, 2004) and negative affect (Anderson, Keltner, \& John, 2003), which suggest that similarity does not contribute to, or has negligible effects on, the couple's relationship satisfaction. 
Although we did not find any significant effects of self-esteem similarity on satisfaction with the relationship, an interesting question is whether the self-esteem of relationship partners is already similar when they begin their relationship (a process called assortative mating; cf. Luo \& Klohnen, 2005; Watson et al., 2004) or whether their self-esteem is similar because partners converge during the course of their relationship (cf. Anderson et al., 2003; Gonzaga, Campos, \& Bradbury, 2007). For example, one study compared couples in different stages of the relationship (e.g., couples with a young child, couples with a grown-up child, etc.) and found that similarity was higher in later stages of the relationship, suggesting convergence over time (Schafer \& Keith, 1992). In contrast, in another study self-esteem similarity was unrelated to the length of the relationship, suggesting that similarity was due to assortative mating (Schumm, Figley, \& Fuhs, 1980). However, regardless of whether self-esteem similarity results from assortative mating or from convergence between partners, the important point in the context of the present review is that the available evidence does not suggest that self-esteem similarity influences the quality of romantic relationships. Nevertheless, even if self-esteem similarity does not influence relationship quality, it is possible that the perception of similarity is beneficial. Murray, Holmes, Bellavia, Griffin, and Dolderman (2002) argue that the mere perception of similarity in selfesteem is sufficient to feel better understood. Thus, perceiving to have similar self-esteem might be more important than actual similarity for a satisfying relationship.

\section{Psychological Mechanisms Accounting for the Link Between Self-Esteem and Relationship Quality}

As yet there is little evidence with regard to the mechanisms that might explain why a person's self-esteem is linked to the quality of his or her romantic relationship. In a study by Murray, Holmes, and Griffin (2000), felt security about the partner's love mediated the effect of self-esteem on relationship satisfaction. In that study, Murray et al. (2000) examined a sample of 
married and cohabiting couples and a sample of dating college students - the latter sample also provided follow-up data four and 12 months later. Both cross-sectional and longitudinal analyses supported the hypothesis that perceived regard mediates the self-esteem effect. More specifically, the results suggested that individuals with low self-esteem think that their partners see them as negatively as they see themselves; therefore, in order to avoid disappointment, they tend to distance themselves, which in turn reduces the relationship satisfaction of both partners. Moreover, the results suggest that, in contrast, individuals with high self-esteem have positive perceptions of their partners' regard, which strengthens relationship well-being.

In our own research, we found that secure romantic attachment between the partners mediated both actor and partner effects of self-esteem on relationship satisfaction (Erol \& Orth, 2013). In this study, secure romantic attachment to the current partner was operationalized as having low levels of attachment-related anxiety and avoidance (see Brennan, Clark, \& Shaver, 1998), both of which contributed independently to the mediation effects. Research suggests that attachment-related anxiety is linked to maladaptive interpersonal behavior such as providing less instrumental support and being less responsive (Collins \& Feeney, 2000). Consequently, if low self-esteem contributes to anxious attachment to the current partner, low self-esteem might indirectly lead to poor caregiving, which in turn may affect the partner's satisfaction with the relationship. Also, if low self-esteem contributes to attachment-related avoidance, then individuals with low self-esteem might tend to reduce the interpersonal closeness with the partner to protect themselves against experiences of rejection (Murray et al., 2000), which might decrease the partner's relationship satisfaction. Furthermore, individuals with high attachment-related avoidance are less attentive to emotional information (Fraley, Garner, \& Shaver, 2000), which may reduce the partner's relationship satisfaction. Also, attachment-related avoidance may lead to 
ineffective support seeking (Collins \& Feeney, 2000), which in turn compromises the individual's own relationship satisfaction.

Although there is evidence that perceived regard and secure attachment between the partners are possible mediating mechanisms that explain the link between self-esteem and relationship satisfaction, it is likely that additional processes are involved. For example, one possible mechanism is excessive reassurance seeking (Joiner \& Metalsky, 2001; Starr \& Davila, 2008). The reason is that people tend to assume that others see the world as they do (e.g., Kenny \& DePaulo, 1993). Consequently, individuals with low self-esteem assume that their partner sees them in the same negative way as they do (Murray et al., 2000), which may elicit worries about being rejected and excessive reassurance seeking (Shaver, Schachner, \& Mikulincer, 2005), which in the long run may decrease the partner's love and commitment to the relationship (Starr \& Davila, 2008).

Another possible mechanism is that people tend to be reluctant in disclosing positive experiences to a partner who has low self-esteem, because they expect a poor and less positive response (MacGregor \& Holmes, 2011). This behavior, however, has negative consequences for the relationship. MacGregor, Fitzsimons, and Holmes (2013) found that individuals who hold back their positive experiences from a partner with low self-esteem reported reduced relationship satisfaction six weeks later. Ironically, individuals with low self-esteem were in fact not less responsive to their partner's good news, so the concerns were unfounded. Thus, these findings suggest that low self-esteem may impair the relationship with the partner through a truly dyadic mechanism.

Also, research suggests that individuals with low self-esteem prefer support that validates their negative views of themselves compared to support that reframes their negative experiences 
positively (Marigold, Cavallo, Holmes, \& Wood, 2014; see also research on self-verification, e.g., Joiner, 1995; Swann, Stein-Seroussi, \& Giesler, 1992). Support providers that offer positive evaluations to partners with low self-esteem tend to sense that their support is not appreciated by their partners and in the long term may become frustrated with the relationship partner. Thus, this mechanism explains how the behavior of individuals with low self-esteem may lead to reduced relationship satisfaction in the partner and, ultimately, may contribute to relationship dissolution.

Finally, a possible mechanism is proposed by M. D. Johnson and Galambos (2014; see also M. D. Johnson \& Anderson, 2013), who suggest that individuals with high self-esteem are more confident about their ability to achieve goals and therefore are likely to be more effective in creating and maintaining a fulfilling and satisfying relationship.

\section{Future Directions and Conclusions}

In this article, we have reviewed theoretical perspectives and available evidence on the link between people's self-esteem and the quality of their romantic relationships. Overall, the evidence suggests that high self-esteem is beneficial in romantic relationships. Furthermore, research using data from both partners of couples suggests that high self-esteem has a positive effect also on the partner's happiness with the relationship. However, research indicates that the degree of self-esteem similarity between partners does not influence the couple's relationship satisfaction. Finally, evidence suggests that perceived regard and secure attachment between the partners may explain why self-esteem is beneficial in romantic relationships.

Although research suggests that self-esteem influences relationship quality, further longitudinal studies are needed that test the hypothesized causal link between the constructs more closely (for the debate about the causality of the relation between self-esteem and life outcomes, see, e.g., Baumeister, Campbell, Krueger, \& Vohs, 2003; Orth \& Robins, 2014; Swann, Chang- 
Schneider, \& McClarty, 2007). Moreover, a problem in many longitudinal studies with nonexperimental designs is that the observed effects may be caused by third variables that were not included in the analyses. Future research in this field should therefore seek to enhance the conclusions with regard to causality, by using experimental designs (e.g., intervention studies) and statistical methods that allow for more efficient control of third variables (e.g., propensity score matching; Rosenbaum \& Rubin, 1983; Thoemmes \& Kim, 2011). In particular, future research should test whether the self-esteem effect on relationship satisfaction holds when controlling for neuroticism. Research suggests, however, that the self-esteem effect on other outcomes, such as depression, is unaltered when neuroticism is controlled for (Sowislo, Orth, \& Meier, 2014).

Furthermore, the field would benefit greatly from a systematic meta-analysis of the available data from longitudinal and experimental studies, which would help drawing more robust conclusions about the direction and size of effects between self-esteem and relationship quality. Moreover, a systematic meta-analysis could make an important contribution by testing possible moderating factors such as length of the relationship. In addition, because most of the available studies focused on relationship satisfaction, there is a need to employ additional indicators of relationship quality. Although relationship satisfaction is a well-validated measure to assess the quality of romantic relationships (Glenn, 2003), the field would benefit if future research would more often use objective measures, behavior observation, and observer ratings (i.e., regarding aspects of relationship quality such as communication, mutual social support, disagreements, and behavior during conflicts and arguments). Future research could also test whether the relation between self-esteem and relationship quality becomes less positive, or even negative, among people who have extremely high self-esteem (i.e., whether high self-esteem has a dark side with regard to romantic relationships; cf. Baumeister, Smart, \& Boden, 1996). It is worth noting, 
however, that research in the field of self-esteem and depression suggests that the adaptive effect of self-esteem is linear across the continuum from low to high self-esteem (i.e., the adaptive effect is not weaker at very high levels of self-esteem; Orth, Robins, Meier, \& Conger, 2015).

Moreover, although research suggests that perceived regard and secure attachment between partners are possible mediating mechanisms of the link between self-esteem and relationship quality, it is possible that further mechanisms are at work, which are equally or more important. Therefore, future research is needed to examine in more detail the mechanisms through which self-esteem contributes to a happy relationship. It is important to note that our own study (Erol \& Orth, 2013), in which we tested whether attachment between romantic partners mediated the link between self-esteem and relationship satisfaction, was based on cross-sectional data and therefore does not allow for causal conclusions with regard to the mediating effect of secure attachment. Therefore, future research on the mediating mechanisms should use longitudinal designs, which allows disentangling the temporal order of predictor, mediator, and outcome (Cole \& Maxwell, 2003; Maxwell \& Cole, 2007).

Also, most of the research reviewed in this article is based on samples from Western countries. Therefore, future studies should replicate the key findings using samples from other cultural contexts, such as Asian and African countries (Arnett, 2008; Henrich, Heine, \& Norenzayan, 2010). For example, research suggests that members of East Asian cultures have lower levels of self-esteem and a lower need for high self-esteem (Heine, Lehman, Markus, \& Kitayama, 1999), which may alter the link between people's self-esteem and the quality of their romantic relationships. Moreover, culture shapes communication behaviors in relationships and thereby influences whether specific behaviors have an effect on relationship satisfaction (Williamson et al., 2012). Therefore, future research should examine the effects of self-esteem on 
relationship quality in samples from diverse cultural contexts to better understand how generalizable the extant findings are.

Finally, future research should test for the effects of other characteristics of self-esteem besides its level (i.e., whether it is high or low), such as self-esteem stability (i.e., the degree of variability of a person's self-esteem across short periods; Kernis, 2005) and self-esteem contingency (i.e., the degree to which a person's self-esteem is influenced by positive and negative external feedback; Crocker \& Wolfe, 2001). For example, it is possible that individuals whose self-esteem fluctuates strongly in daily life show more problematic behavior in romantic relationships, regardless of whether their self-esteem is high or low.

The meta-analytic findings reported in this article might be useful for power calculations in the planning of future research studies. For example, using the web-based power calculator by Kenny and Ackerman (2015; cf. Ackerman, Ledermann, \& Kenny, 2015), the present findings suggest that, when testing for partner effects of self-esteem on relationship quality, a sample size of 156 couples is needed for a power level of .80, assuming that the residuals of the explained variables are correlated at .30 .

The findings on the link between self-esteem and relationship quality have implications for counseling and therapy in the context of relationship problems, suggesting that it may be worthwhile to consider both partners' self-esteem. Clearly, as self-esteem is a relatively stable personality characteristic (Kuster \& Orth, 2013; Trzesniewski et al., 2003), it is not an easy task to increase a client's self-esteem. Nevertheless, research on self-esteem interventions suggests that it is possible to improve people's self-esteem (Haney \& Durlak, 1998; O’Mara, Marsh, Craven, \& Debus, 2006). With regard to the relationship context, research suggests that some negative consequences of low self-esteem could be circumvented more easily (Marigold, Holmes, 
\& Ross, 2010). For example, individuals with low self-esteem tended to react to relationshipthreatening circumstances by self-protective and relationship-destructive behaviors. However, through reframing the partner's compliments in a more meaningful way, individuals with low self-esteem were able to reduce the threat and engage in more constructive behaviors towards their partners (Marigold et al., 2010).

In conclusion, research suggests that having high self-esteem is beneficial for people's romantic relationships. However, further evidence is needed with regard to the hypothesized causality of the relation. Moreover, future research should continue to examine the mechanisms by which self-esteem influences the quality of romantic relationships. Understanding the link between self-esteem and relationship quality will help to develop more effective interventions aimed at preventing relationship problems and fostering satisfying relationships. 


\section{References}

Ackerman, R. A., Ledermann, T., \& Kenny, D. A. (2015). Power analysis for the actor-partner interdependence model. Manuscript in preparation.

Ackerman, R. A., Witt, E. A., Donnellan, M. B., Trzesniewski, K. H., Robins, R. W., \& Kashy, D. A. (2011). What does the Narcissistic Personality Inventory really measure? Assessment, 18, 67-87.

Anderson, C., Keltner, D., \& John, O. P. (2003). Emotional convergence between people over time. Journal of Personality and Social Psychology, 84, 1054-1068.

Arnett, J. J. (2008). The neglected 95\%: Why American psychology needs to become less American. American Psychologist, 63, 602-614.

Barnett, L. R., \& Nietzel, M. T. (1979). Relationship of instrumental and affectional behaviors and self-esteem to marital satisfaction in distressed and nondistressed couples. Journal of Consulting and Clinical Psychology, 47, 946-957.

Baumeister, R. F., Campbell, J. D., Krueger, J. I., \& Vohs, K. D. (2003). Does high self-esteem cause better performance, interpersonal success, happiness, or healthier lifestyles? Psychological Science in the Public Interest, 4, 1-44.

Baumeister, R. F., \& Leary, M. R. (1995). The need to belong: Desire for interpersonal attachment as a fundemental human motivation. Psychological Bulletin, 117, 497-529.

Baumeister, R. F., Smart, L., \& Boden, J. M. (1996). Relation of threatened egotism to violence and aggression: The dark side of high self-esteem. Psychological Review, 103, 5-33.

Bradbury, T. N., Fincham, F. D., \& Beach, S. R. H. (2000). Research on the nature and determinants of marital satisfaction: A decade in review. Journal of Marriage and Family, $62,964-980$. 
Brennan, K. A., Clark, C. L., \& Shaver, P. R. (1998). Self-report measurement of adult romantic attachment: An integrative overview. In J. A. Simpson \& W. S. Rholes (Eds.), Attachment theory and close relationships (pp. 46-76). New York, NY: Guilford Press.

Brown, M. A., \& Brown, J. D. (2015). Self-enhancement biases, self-esteem, and ideal mate preferences. Personality and Individual Differences, 74, 61-65.

Cohen, J. (1988). Statistical power analysis for the behavioral sciences. Hillsdale, NJ: Erlbaum

Cole, D. A., \& Maxwell, S. E. (2003). Testing mediational models with longitudinal data: Questions and tips in the use of structural equation modeling. Journal of Abnormal Psychology, 112, 558-577.

Collins, N. L., \& Feeney, B. C. (2000). A safe haven: An attachment theory perspective on support seeking and caregiving in intimate relationships. Journal of Personality and Social Psychology, 78, 1053-1073.

Cramer, D. (2003). Acceptance and need for approval as moderators of self-esteem and satisfaction with a romantic relationship or closest friendship. The Journal of Psychology, $137,495-505$.

Crocker, J., \& Wolfe, C. T. (2001). Contingencies of self-worth. Psychological Review, 108, 593623.

Donnellan, M. B., Kenny, D. A., Trzesniewski, K. H., Lucas, R. E., \& Conger, R. D. (2012). Using trait-state models to evaluate the longitudinal consistency of global self-esteem from adolescence to adulthood. Journal of Research in Personality, 46, 634-645.

Donnellan, M. B., Trzesniewski, K. H., Conger, K. J., \& Conger, R. D. (2007). A three-wave longitudinal study of self-evaluations during young adulthood. Journal of Research in Personality, 41, 453-472. 
Dryer, D. C., \& Horowitz, L. M. (1997). When do opposites attract? Interpersonal complementarity versus similarity. Journal of Personality and Social Psychology, 72, 592-603.

Dyrenforth, P. S., Kashy, D. A., Donnellan, M. B., \& Lucas, R. E. (2010). Predicting relationship and life satisfaction from personality in nationally representative samples from three countries: The relative importance of actor, partner, and similarity effects. Journal of Personality and Social Psychology, 99, 690-702.

Elfhag, K., Tynelius, P., \& Rasmussen, F. (2010). Self-esteem links in families with 12-year-old children and in separated spouses. The Journal of Psychology, 144, 341-359.

Erol, R. Y., \& Orth, U. (2013). Actor and partner effects of self-esteem on relationship satisfaction and the mediating role of secure attachment between the partners. Journal of Research in Personality, 47, 26-35.

Erol, R. Y., \& Orth, U. (2014). Development of self-esteem and relationship satisfaction in couples: Two longitudinal studies. Developmental Psychology, 50, 2291-2230.

Fincham, F. D., \& Bradbury, T. N. (1993). Marital satisfaction, depression, and attributions: A longitudinal analysis. Journal of Personality and Social Psychology, 64, 442-452.

Fraley, R. C., Garner, J. P., \& Shaver, P. R. (2000). Adult attachment and the defensive regulation of attention and memory: Examining the role of preemtive and postemptive defensive processes. Journal of Personality and Social Psychology, 79, 816-826.

Gattis, K. S., Berns, S., Simpson, L. E., \& Christensen, A. (2004). Birds of a feather or strange birds? Ties among personality dimensions, similarity, and marital quality. Journal of Family Psychology, 18, 564-574. 
Glenn, N. D. (2003). Marital quality. In J. J. Ponzetti (Ed.), International Encyclopedia of Marriage and Family (Second ed., Vol. 3, pp. 1070-1078). New York, NY: Macmillan Reference USA.

Gonzaga, G. C., Campos, B., \& Bradbury, T. N. (2007). Similarity, convergence, and relationship satisfaction in dating and married couples. Journal of Personality and Social Psychology, 93, 34-48.

Haney, P., \& Durlak, J. A. (1998). Changing self-esteem in children and adolescents: A metaanalytic review. Journal of Clinical Child Psychology, 27, 423-433.

Harter, S. (2006). The self. In N. Eisenberg (Ed.), Handbook of child psychology (Vol 3): Social, emotional, and personality development (pp. 505-570). Hoboken, NJ: Wiley.

Heine, S. J., Lehman, D. R., Markus, H. R., \& Kitayama, S. (1999). Is there a universal need for positive self-regard? Psychological Review, 106, 766-794.

Henrich, J., Heine, S. J., \& Norenzayan, A. (2010). The weirdest people in the world? Behavioral and Brain Sciences, 33, 61-83.

Heyman, R. E., Sayers, S. L., \& Bellack, A. S. (1994). Global marital satisfaction versus marital adjustment: An empirical comparison of three measures. Journal of Family Psychology, 8, 432-446.

Johnson, M. D., \& Anderson, J. R. (2013). The longitudinal association of marital confidence, time spent together, and marital satisfaction. Family process, 52, 244-256.

Johnson, M. D., \& Galambos, N. L. (2014). Paths to intimate relationship quaity from parentadolescent relations and mental health. Journal of Marriage and Family, 76, 145-160.

Joiner, T. E. (1995). The price of soliciting and receiving feedback: Self-verification theory as a vulnerability to depression theory. Journal of Abnormal Psychology, 104, 364-372. 
Joiner, T. E., \& Metalsky, G. I. (2001). Excessive reassurance seeking: Delineating a risk factor involved in the development of depressive symptoms. Psychological Science, 12, 371378.

Jones, J. T., \& Cunningham, J. D. (1996). Attachment styles and other predictors of relationship satisfaction in dating couples. Personal Relationships, 3, 387-399.

Judge, T. A., \& Hurst, C. (2008). How the rich (and happy) get richer (and happier): Relationship of core self-evaluations to trajectories in attaining work success. Journal of Applied Psychology, 93, 849-863.

Karney, B. R., \& Bradbury, T. N. (1997). Neuroticism, marital interaction, and the trajectory of marital satisfaction. Journal of Personality and Social Psychology, 72, 1075-1092.

Kenny, D. A., \& Ackerman, R. A. (2015). APIM Power [Web-based software]. Retrieved from https://robert-ackerman.shinyapps.io/APIMPowerR/.

Kenny, D. A., \& Cook, W. (1999). Partner effects in relationship research: Conceptual issues, analytic difficulties, and illustrations. Personal Relationships, 6, 1350-4126.

Kenny, D. A., \& DePaulo, B. M. (1993). Do people know how others view them? An empirical and theoretical account. Psychological Bulletin, 114, 145-161.

Kenny, D. A., Kashy, D. A., \& Cook, W. L. (2006). Dyadic data analysis. New York, NY: Guilford Press.

Kenny, D. A., \& Ledermann, T. (2010). Detecting, measuring, and testing dyadic patterns in the actor-partner interdependence model. Journal of Family Psychology, 24, 359-366.

Kernis, M. H. (2005). Measuring self-esteem in context: The importance of stability of selfesteem in psychological functioning. Journal of Personality, 73, 1569-1605.

Kuster, F., \& Orth, U. (2013). The long-term stability of self-esteem: Its time-dependent decay and nonzero asymptote. Personality and Social Psychology Bulletin, 39, 677-690. 
Kuster, F., Orth, U., \& Meier, L. L. (2013). High self-esteem prospectively predicts better work conditions and outcomes. Social Psychological and Personality Science, 4, 668-675.

Lavner, J. A., Bradbury, T. N., \& Karney, B. R. (2012). Incremental change or initial differences? Testing two models of marital deterioration. Journal of Family Psychology, 26, 606-616.

Leary, M. R. (2004). The sociometer, self-esteem, and the regulation of interpersonal behavior. In R. F. Baumeister \& K. D. Vohs (Eds.), Handbook of self-regulation: Research, theory, and applications (pp. 373-391). New York, NY: The Guilford Press.

Leary, M. R. (2012). Sociometer theory. In P. A. M. Van Lange, A. W. Kruglanski, \& E. T. Higgins (Eds.), Handbook of theories of social psychology (pp. 141-159). Thousand Oaks, CA: Sage.

Leary, M. R., \& Baumeister, R. F. (2000). The nature and function of self-esteem: Sociometer theory. In M. P. Zanna (Ed.), Advances in Experimental Social Psychology (Vol. 32, pp. 1-62). San Diego, CA: Academic Press.

Lipsey, M. W., \& Wilson, D. B. (2001). Practical meta-analysis. Thousand Oaks, CA: Sage.

Luo, S., \& Klohnen, E. C. (2005). Assortative mating and marital quality in newlyweds: A couple-centered approach. Journal of Personality and Social Psychology, 88, 304-326.

MacGregor, J. C. D., Fitzsimons, G. M., \& Holmes, J. G. (2013). Perceiving low self-esteem in close others impedes capitilization and undermines the relationship. Personal Relationships, 20, 690-705.

MacGregor, J. C. D., \& Holmes, J. G. (2011). Rain on my parade: Perceiving low self-esteem in close others hinders positive self-disclosure. Social Psychological and Personality Science, 2, 523-530. 
Marigold, D. C., Cavallo, J. V., Holmes, J. G., \& Wood, J. V. (2014). You can't always give what you want: The challenge of providing social support to low self-esteem individuals. Journal of Personality and Social Psychology, 107, 56-80.

Marigold, D. C., Holmes, J. G., \& Ross, M. (2010). Fostering relationship resilience: An intervention for low self-esteem individuals. Journal of Experimental Social Psychology, 46, 624-630.

Marshall, S. L., Parker, P. D., Ciarrochi, J., \& Heaven, P. C. L. (2014). Is self-esteem a cause or consequence of social support? A 4-year longitudinal study. Child Development, 85, 1275-1291.

Maxwell, S. E., \& Cole, D. A. (2007). Bias in cross-sectional amalyses of longitudinal mediation. Psychological Methods, 12, 23-44.

Mund, M., Finn, C., Hagemeyer, B., Zimmermann, J., \& Neyer, F. J. (2015). The dynamics of self-esteem in partner relationships. European Journal of Personality, 29, 235-249.

Murray, S. L., Holmes, J. G., Bellavia, G. M., Griffin, D. W., \& Dolderman, D. (2002). Kindred spirits? The benefit of egocentrism in close relationships. Journal of Personality and Social Psychology, 82, 563-581.

Murray, S. L., Holmes, J. G., \& Griffin, D. W. (1996a). The benefits of positive illusions: Idealization and the construction of satisfaction in close relationships. Journal of Personality and Social Psychology, 70, 79-98.

Murray, S. L., Holmes, J. G., \& Griffin, D. W. (1996b). The self-fulfilling nature of positive illusions in romantic relationships: Love is not blind, but prescient. Journal of Personality and Social Psychology, 71, 1155-1180. 
Murray, S. L., Holmes, J. G., \& Griffin, D. W. (2000). Self-esteem and the quest for felt security: How perceived regard regulates attachment processes. Journal of Personality and Social Psychology, 78, 478-498.

Neyer, F. J., \& Asendorpf, J. B. (2001). Personality-relationship transaction in young adulthood. Journal of Personality and Social Psychology, 81, 1190-1204.

O’Mara, A. J., Marsh, H. W., Craven, R. G., \& Debus, R. L. (2006). Do self-concept interventions make a difference? A synergistic blend of construct validation and metaanalysis. Educational Psychologist, 41, 181-206.

Orbuch, T. L., House, J. S., Mero, R. P., \& Webster, P. S. (1996). Marital quality over the life course. Social Psychology Quarterly, 59, 162-171.

Orth, U., \& Robins, R. W. (2014). The development of self-esteem. Current Directions in Psychological Science, 23, 381-387.

Orth, U., Robins, R. W., Meier, L. L., \& Conger, R. D. (2015). Refining the vulnerability model of low self-esteem and depression: Disentangling the effects of genuine self-esteem and narcissism. Journal of Personality and Social Psychology, Advance online publication.

Orth, U., Robins, R. W., \& Widaman, K. F. (2012). Life-span development of self-esteem and its effects on important life outcomes. Journal of Personality and Social Psychology, 102, 1271-1288.

Raudenbush, S. W. (2009). Analyzing effect sizes: Random-effects models. In H. Cooper, L. V. Hedges, \& J. C. Valentine (Eds.), The handbook of research synthesis and meta-analysis New York, NY: Russell Sage Foundation.

Robinson, K. J., \& Cameron, J. J. (2012). Self-esteem is a shared relationship resource: Additive effects of dating partners' self-esteem levels predict relationship quality. Journal of Research in Personality, 46, 227-230. 
Rosenbaum, D. R., \& Rubin, D. B. (1983). The central role of the propensity score in observational studies for causal effects. Biometrika, 70, 41-55.

Rosenberg, M. (1965). Society and the adolescent self-image. Princeton, NJ: Princeton University Press.

Salmela-Aro, K., \& Nurmi, J. E. (2007). Self-esteem during university studies predict career characteristics 10 years later. Journal of Vocational Behavior, 70, 463-477.

Schafer, R. B., \& Keith, P. M. (1992). Self-esteem agreement in the marital relationship. The Journal of Social Psychology, 132, 5-9.

Schaffhuser, K., Wagner, J., Lüdtke, O., \& Allemand, M. (2014). Dyadic longitudinal interplay between personality and relationship satisfaction: A focus on neuroticism and self-esteem. Journal of Research in Personality, 53, 124-133.

Schumm, W. R., Figley, C. R., \& Fuhs, N. N. (1980). Similarity in self-esteem as a function of duration of marriage among student couples. Psychological Reports, 47, 365-366.

Sciangula, A., \& Morry, M. M. (2009). Self-esteem and perceived regard: How I see myself affects my relationship satisfaction. The Journal of Social Psychology, 149, 143-158.

Shackelford, T. K. (2001). Self-esteem in marriage. Personality and Individual Differences, 30, 371-390.

Shaver, P. R., Schachner, D. A., \& Mikulincer, M. (2005). Attachment style, excessive reassurance seeking, relationship processes, and depression. Personality and Social Psychology Bulletin, 31, 343-359.

Sowislo, J. F., \& Orth, U. (2013). Does low self-esteem predict depression and anxiety? A metaanalysis of longitudinal studies. Psychological Bulletin, 139, 213-240. 
Sowislo, J. F., Orth, U., \& Meier, L. L. (2014). What constitutes vulnerable self-esteem?

Comparing the prospective effects of low, unstable, and contingent self-esteem on depressive symptoms. Journal of Abnormal Psychology, 123, 737-753.

Spanier, G. B., \& Lewis, R. A. (1980). Marital quality: A review of the seventies. Journal of Marriage and Family, 42, 825-839.

Starr, L. R., \& Davila, J. (2008). Excessive reassurance seeking, depression, and interpersonal rejection: A meta-analytic review. Journal of Abnormal Psychology, 117, 762-775.

Stinson, D. A., Logel, C., Zanna, M. P., Holmes, J. G., Cameron, J. J., Wood, J. V., \& Spencer, S. J. (2008). The cost of lower self-esteem: Testing a self- and social-bonds model of health. Journal of Personality and Social Psychology, 94, 412-428.

Swann, W. B., \& Bosson, J. K. (2010). Self and identity. In S. T. Fiske, D. T. Gilbert, \& G. Lindzey (Eds.), Handbook of social psychology (Vol. 1, pp. 589-628). Hoboken, NJ: Wiley.

Swann, W. B., Chang-Schneider, C., \& McClarty, K. L. (2007). Do people's self-view matter? American Psychologist, 62, 84-94.

Swann, W. B., Stein-Seroussi, A., \& Giesler, R. B. (1992). Why people self-verify. Journal of Personality and Social Psychology, 62, 392-401.

Tackett, S. L., Nelson, L. J., \& Busby, D. M. (2013). Shyness and relationship satisfaction: Evaluating the associations between shyness, self-esteem, and relationship satisfation in couples. The American Journal of Family Therapy, 41, 34-45.

Thoemmes, F. J., \& Kim, E. S. (2011). A systematic review of propensity score methods in the social sciences. Multivariate Behavioral Research, 46, 90-118. 
Trzesniewski, K. H., Donnellan, M. B., Moffitt, T. E., Robins, R. W., Poulton, R., \& Caspi, A. (2006). Low self-esteem during adolescence predicts poor health, criminal behavior, and limited economic prospects during adulthood. Developmental Psychology, 42, 381-390.

Trzesniewski, K. H., Donnellan, M. B., \& Robins, R. W. (2003). Stability of self-esteem across the life span. Journal of Personality and Social Psychology, 84, 205-220.

Trzesniewski, K. H., Donnellan, M. B., \& Robins, R. W. (2013). Development of self-esteem. In V. Zeigler-Hill (Ed.), Self-esteem (pp. 60-79). London: Psychology Press.

VanLaningham, J., Johnson, D. R., \& Amato, P. (2001). Marital happiness, marital duration, and the U-shaped curve: Evidence from a five-wave panel study. Social Forces, 78, 13131341.

Voss, K., Markiewicz, D., \& Doyle, A. B. (1999). Friendship, marriage, and self-esteem. Journal of Social and Personal Relationships, 16, 103-122.

Watson, D., Klohnen, E. C., Casillas, A., Nus Simms, E., Haig, J., \& Berry, D. S. (2004). Match makers and deal breakers: Analyses of assortative mating in newlywed couples. Journal of Personality, 72, 1029-1068.

Whisman, M. A., Uebelacker, L. A., Tolejko, N., Chatav, Y., \& McKelvie, M. (2006). Marital discord and well-being in older adults: Is the association confounded by personality? Psychology and Aging, 21, 626-631.

Williamson, H. C., Ju, X., Bradbury, T. N., Karney, B. R., Fang, X., \& Liu, X. (2012). Communication behavior and relationship satisfaction among American and Chinese newlywed couples. Journal of Family Psychology, 26, 308-315.

Zeigler-Hill, V. (2010). The interpersonal nature of self-esteem: Do different measures of selfesteem possess similar interpersonal content? Journal of Research in Personality, 44, $22-$ 30. 
Table 1

Meta-Analytic Aggregation of Actor and Partner Effects of Self-Esteem (SE) on Relationship Satisfaction (RS) and of the Correlation between the Partners' SE, Based on the Findings Reported in Erol and Orth (2013)

Weighted mean

Effect $\quad$ effect size $\quad 95 \%$ CI Homogeneity $(Q)$

\begin{tabular}{lccc}
\hline Actor effect of SE on $\mathrm{RS}^{\mathrm{a}}$ & $.26^{*}$ & {$[.16, .36]$} & $26.1^{*}$ \\
Partner effect of SE on $\mathrm{RS}^{\mathrm{a}}$ & $.15^{*}$ & {$[.08, .21]$} & $9.1^{*}$ \\
Correlation between partners' SE & $.15^{*}$ & {$[.12, .17]$} & 3.7
\end{tabular}

Note. Computations were made with a random-effects model. For all meta-analytic computations, the number of studies was $k=5$ and the total number of participants was 7,079. CI $=$ confidence interval.

${ }^{\text {a }}$ Standardized regression coefficient.

$* p<.05$. 
Table 2

Meta-Analytic Aggregation of the Effects of Growth Factors of Self-Esteem (SE) on Growth Factors of Relationship Satisfaction (RS), Based on the Findings Reported in Erol and Orth (2014)

\section{Weighted mean}

Effect $\quad$ effect size ${ }^{\mathrm{a}} \quad 95 \%$ CI $\quad$ Homogeneity $(Q)$

\begin{tabular}{llll}
\hline Effect of SE intercept on RS intercept & $.29^{*}$ & {$[.19, .39]$} & $9.2^{*}$ \\
Effect of SE slope on RS slope & $.24 *$ & {$[.22, .26]$} & 0.0
\end{tabular}

Note. Computations were made with a random-effects model. For all meta-analytic computations, the number of studies was $k=2$ and the total number of participants was 7,001. CI $=$ confidence interval.

a Standardized regression coefficient.

$* p<.05$. 


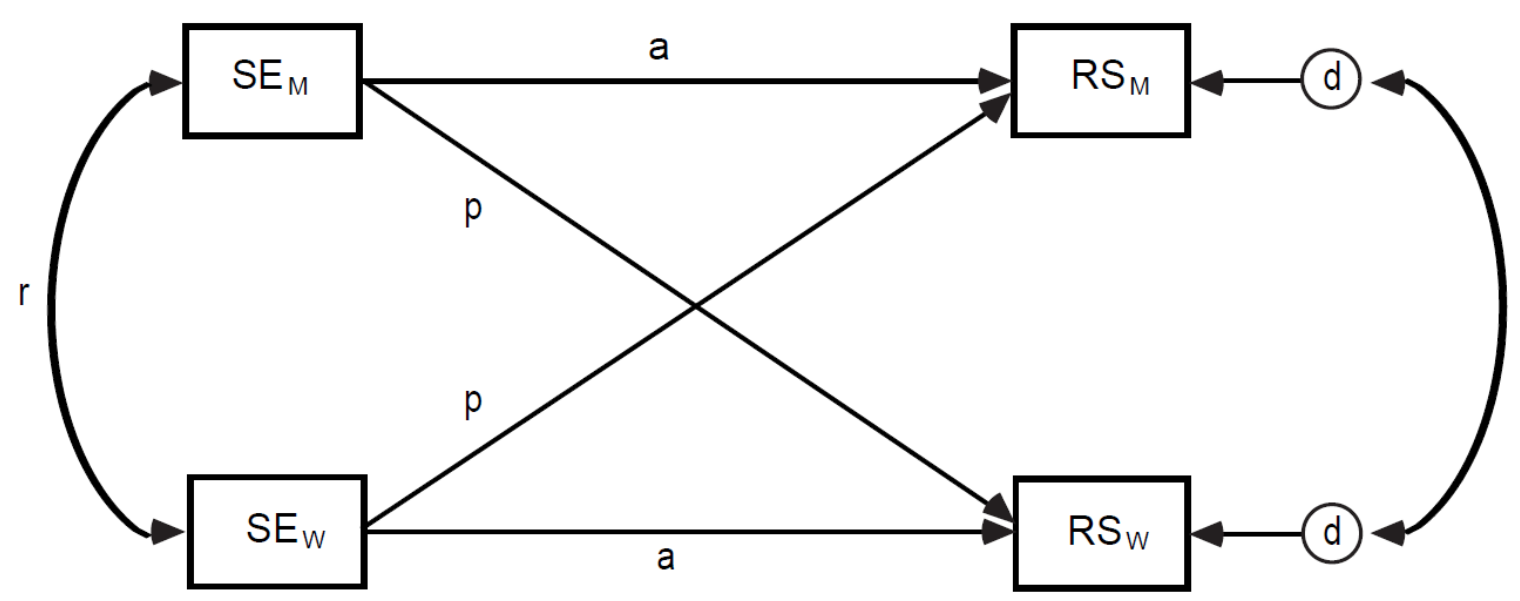

Figure 1. Actor-partner interdependence model of self-esteem (SE) predicting relationship satisfaction (RS). Subscripts of variables denote whether the variable belongs to the male partner (M) or female partner (W). $a=$ actor effect of a person's self-esteem on his or her own relationship satisfaction; $p=$ partner effect of a person's self-esteem on his or her partner's relationship satisfaction. 